[Bull. Agr. Chem. Soc. Japan, Vol. 24, No. 6, p. 588 594, 1960]

\title{
Studies on Lactic Acid Fermentation
}

\author{
Part III. Mechanism of Ethanol Formation* \\ By Hideo Katagiri, Kazutami Imai and Katsumi Ito \\ Department of Agricultural Chemistry, Faculty of Agriculture, Kyoto University, Kyoto \\ Received March 16, 1960
}

\begin{abstract}
Pyruvate and acetaldehyde were detected as intermediates in the pathway of heterolactic fermentation in the presence of semicarbazide by resting cells of $L$. fermenti. Alcohol dehydrogenase in ammonium sulfate fraction catalyzes both DPN- and TPN- linked dehydrogenation of ethanol to acetaldehyde, and acetyl coenzyme A was reduced to acetaldehyde in the presence of either TPN or DPN. By coupling of xylose degradation with mannitol utilization or by the continuous supply of reduced methyl viologen, appreciable increase of ethyl alcohol was observed.
\end{abstract}

Acetaldehyde dehydrogenase was reported with Clostridium kluyveri' ${ }^{\mathrm{I}}$, and with Escherichia coli ${ }^{2}$, which is absolutely dependent on DPN and coenzyme $\mathrm{A}(\mathrm{CoA})$. It is possible to assume that in heterolactic fermentation acetyl phosphate (or acetyl coenzyme A) produced from xylulose-5-phosphate by phosphoketolase can be reduced up to ethanol when four hydrogen atoms are supplied as if ethanol were produced from glucose.

In the present paper, intermediary formation of acetaldehyde and interconversion of acetyl phosphates, acetaldehyde and ethanol by the extract of Lactobacillus fermenti are investigated.

\section{MATERIALS AND METHODS}

Preparation of enzyme solution: $L$. fermenti was grown and harvested as previously described ${ }^{3)}$. Cells were disintegrated with sonic oscillator for thirty minutes and centrifuged with Spinco centrifuge at $21,000 \mathrm{rpm}$ for thirty minutes. Glutathione $\left(2 \times 10^{-4} \mathrm{M}\right)$ was added to the supernatant then solid ammonium

* Presented at the General Meeting of the Agricultural Chemical Society of Japan, Kyoto, May 8, 1958, and Tokyo, April 6, 1960.

1) R.M. Burton and E.R. Stadtman, J. Biol. Chem., 202, 873 (1.953).

2) E.A. Dawes and S.M. Foster, Biochim. et Biophys. Acta, 22, $252(1956)$.

3) H. Katagiri, K. Imai and K. Ito, This Bulletin, 24, 575 $(1960)$, sulfate was added to $25 \sim 80 \%$ saturation, and the resulted precipitate was centrifuged. The gathered fraction was dissolved in tris buffer $(0.05 \mathrm{M}, \mathrm{pH} 7.8)$ and dialyzed overnight against 150 volumes of the same buffer containing $2.0 \times 10^{-4} \mathrm{M}$ glutathione. The enzyme solution was then treated with 0.2 volume of Dowex-1 resin for twenty minutes at $2^{\circ} \mathrm{C}$ and stored in deep freeze.

Analytical : Methyl viologen chloride was synthesized by the procedure of Smith). Platinum asbestos (30\%) was commercial material. Acetaldehyde was measured by the method of Barker and Summerson ${ }^{5)}$. Coenzyme A was prepared by the procedure of Stadtman and Kornberg ${ }^{6)}$, acetyl phosphate and acetyl CoA were synthesized by the methods of Avison ${ }^{7)}$ and Simon and Shemin ${ }^{8}$, and were estimated by the method of Kaplan and Lipmann ${ }^{9)}$. Other analytical methods were the same as described in the previous paper ${ }^{3)}$.

\section{RESULTS}

Suspension of resting cells of L. fermenti which are harvested from malt extract showed vigorous consumption of glucose to give lactic

4) C.R. Smith, J. An, Chem. Soc., 48, 414 (1924).

5) D.B. Barker and W.H. Summerson, J. Biol. Chem., 138, 535 (1941).

6) E.R. Stadman and A. Komberg, J. Biol. Chem., 203, 47 (1953).

7) A.W.D. Avison, J. Cbem. Soc. (London), 1955, 732.

8) E. Simon and J.D. Shemin, J. Am. Cbem. Sot, 75, 2520 (1953).

9) N.O. Kaplan and F. Lipman, J. Biol. Chent., 164, 37 (1948), 
Table 1. Intermediary Production of Pyruvate AND ACETALDEHYDE FROM GLUCOSE

Products ( $\mu \mathrm{mol})$

Expt. Glucose

No. utilized Lactate Ethanol Acetate Pyruvate Acetal-

$\begin{array}{rlrrrrr} & & & & & & \text { dehyd } \\ 1 & 1,000 & 762 & 874 & 120 & 163 & 50 \\ 2 & 1,000 & 922 & 943 & 88 & 2 & 0 \\ 3 & - & 23 & 0 & 0 & 0 & 0\end{array}$

Reaction mixture contained: glucose, 1,000 Hmoles; semicar-

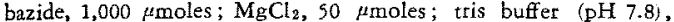
3.0 mmoles; phosphate beffer ( $\mathrm{pH} 7.8$ ), 3.0 mmoles; resting cells of $L$. fermenti, $340 \mathrm{mg}$ in a final volume of $50 \mathrm{~mL}$. The mixture was incubated statically at $37^{\circ} \mathrm{C}$. Expt. 1, complete system; Expt. 2, without semicarbazide; Expt. 3, without substrate.

acid, ethanol, carbon dioxide and small amounts of acetic acid (Table I). If excess of semicarbazide was added to the reaction mixture from the beginning of glucose utilization, intermediary production of pyruvate as well as acetaldehyde occurred due to the formation of each semicarbazones, which were identified with the authentic samples by the paperchromatogram, by melting point, or by elemental analysis [Found: C, 40.20; H, 2.96; N, 20.0. Calcd. for $\mathrm{C}_{9} \mathrm{H}_{8} \mathrm{~N}_{4} \mathrm{O}_{6}$ (pyruvic 2, 4-dinitrophenyl hydrazone): $\mathrm{C}, 40.30 ; \mathrm{H}, 2.99 ; \mathrm{N}, 20.9 \%$. Found: C, 42.73; H, 3.71; N, 24.9. Calcd. for $\mathrm{C}_{8} \mathrm{H}_{8} \mathrm{~N}_{4} \mathrm{O}_{4}$ (acetaldehyde 2, 4-dinitrophenyl hydrazone) : $\mathrm{C}, 42.86, \mathrm{H}, 3.60$; N, 25.1\%].

The amount of pyruvate trapped as the semicarbazone is in relative proportion to the decrease of lactic acid and that of acetaldehyde in proportion to the decrease of ethanol formation. These results suggest that pyruvate seems to be an obligatory precursor of lactic acid, whereas ethyl alcohol formed in glucose fermentation may result from the reduction of acetaldehyde. Whether acetaldehyde detected as an intermediate is bound with a sulfhydryl group such as $\mathrm{CoA}$ in its active reduction to ethanol will be discussed later.

When ethanol is aerobically contacted with the resting cells of L. fermenti in phosphate buffer only a part of ethanol is consumed for several hours to give acetic acid, whereas if excess of semicarbazide is present, appreciable production of acetaldehyde is demonstrated as
TABLE II. ACCUMULATION OF ACETALDEHYDE in the Oxidation of Ethanol

$\begin{array}{cccc}\text { Expt. No. } & \begin{array}{c}\text { Ethanol } \\ \text { utilized } \\ \mu \mathrm{mol}\end{array} & \begin{array}{c}\text { Acetate } \\ \text { formed } \\ \mu \mathrm{mol}\end{array} & \begin{array}{c}\text { Acetaldehyde } \\ \text { formed }\end{array} \\ 1 & 176 & 48 & \mu \mathrm{mol} \\ 2 & 43 & 25 & 03 \\ 3 & - & 0 & 0\end{array}$

Reaction mixtura coatained: echanol, 1 rnmole; $\mathrm{MgCl}_{2}$, 50 $\mu$ moles; tris buffer ( $\mathrm{pH} 7.8$ ), $200 \mu$ moles; phosphate buffer ( $\mathrm{pH}$ 8.0), 1.5 mmole; resting cells, $410 \mathrm{mg}$; semicarbazide, 1 mmole ; in a total volume of $50 \mathrm{ml}$. Iacubation was carried out aerobically at $30^{\circ} \mathrm{C}$ for 5 hours on a shaking incubator. Expt. 1, com. plete system; Expr. 2, without semicrbazide; Expt. 3, without substrate.

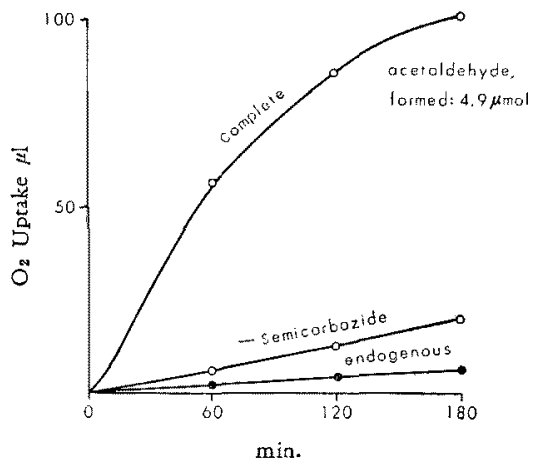

Frg. 1. Oxidation of Ethanol by Resting Cells of $L$. fermenti.

Each Warburg cup contained : $100 \mu$ moles of phosphate buffer ( $\mathrm{pH}$ 7.0), 5 pmoles of $\mathrm{MgCl}_{2}$, 50 mrooles of ethanol, resring cells, $15 \mathrm{mg}$ in a total volume of $2.3 \mathrm{ml}$. Gas phase, air; temperature, $37^{\circ} \mathrm{C}$.

a direct intermediate to acetic acid (Table II). The similar results were observed in the manometric experiments (Fig. 1). These data show that oxygen uptake due to the utilization of the substrate is accelerated by the addition of large excess of semicarbazide, followed by the trapping of the simple precursor. After incubation, the contents of every Warburg cup was analyzed to estimate cumultive amounts of acetaldehyde as an intermediate. These data are presented in Fig. 1.

Although resting cells of $L$. fermenti can hardly utilize acetaldehyde anaerobically as a sole carbon source, it is observed that when acetaldehyde is added to the system, in which vigorous fermentation of glucose is proceeding, approximately one-third of added acetaldedyde 
TABLE III. DISMUTATION OF ACETALDEHYDE to ETHANOL AND ACETATE

Substrate utilized $(\mu \mathrm{mol}) \quad$ End products $(\mu \mathrm{mol})$

Expt. No. Glucose Acetal- Lactate Ethanol Acetate dehyde

$\begin{array}{rrrrr}970 & 374 & 915 & 1,045 & 310 \\ 1,000 & - & 930 & 883 & 134 \\ - & 18 & 37 & 0 & 0 \\ - & - & 42 & 0 & 0\end{array}$

Reaction mixture contained: phosphate buffer (pH 7.5), 250 $\mu$ moles; tris buffer (pH 7.8), $200 \mu$ moles; glucose, 1 mmole; acetaldehyde, $1 \mathrm{mmole}$ : $\mathrm{MgCl}_{2}, 50 \mu$ moles; $\mathrm{MnSO}_{4}, 15 \mu$ moles; $\mathrm{CaCO}_{9}, 200 \mathrm{mg}$; resting cells, $300 \mathrm{mg}$; in $85 \mathrm{ml}$. Static incubationw as carried out at $30^{\circ} \mathrm{C}$ for 5 hours. Expt. 1 , complete system; Expt. 2, without acetaldehyde; Expt. 3, without glucose; Expt.

4, without both substrates.

TABLE IV. Formation OF ACETYL Compounds FROM ACETALDEHYDE

Reactant omitted

None

TPN (or DPN)

$\mathrm{CoA}$

Glutathione

Phosphate

Acetaldehyde

Extracts

Reaction mixture contained : tris buffer (pH 7.8), 40 pmoles; phosphate buffer $(\mathrm{pH} 8.0) .35 \mu$ moles; dialyzed extracts, $0.5 \mathrm{ml}$ TPN (or DPN), $0.23 \mu$ moles; CoA, 28 units; aceraldehyde 220 umoles; glutarhione, 24 unoles; hydroxylamine, 100 pmoles; in $10 \mathrm{ml}$. Static incubation was carried out at $30^{\circ} \mathrm{C}$ for 3 hours.

disappears and that a dismutation of acetaldehyde to ethanol and acetate takes place (Table III).

Grude extracts of $L$. fermenti is able to utilize small amount of acetaldehyde, in the presence of TPN (or DPN), CoA, glutathione, orthophosphate and large excess of acetaldehyde (Table IV) and produce acetyl compounds (i.e. acetyl CoA or acetyl phosphate) as intermediates to acetic acid, which were detected and assayed after being derived to acetohydroxamate, which gave $\mathrm{R}_{F} 0.52$ with solvent system; watersaturated butanol. These results indicate that several cofactors listed in Table IV would be necessary for the oxidation of acetaldehyde to acetate, since any anionic cofactors are not available in these extracts used for these experiments after treatment with Dowex-l resin.
Among these cofactors, TPN (or DPN) and CoA seem indispensable for the oxidation of the substrate, while glutathione appears to serve only for the reduction of CoA to CoASH, and inorganic phosphate for the conversion of acetyl CoA to acetyl phosphate.

The crude extracts of $L$. fermenti are also able to oxidize ethanol with the addition of large excess of semicarbazide. The enzyme preparation (ammonium sulfate fraction) also oxidize ethanol with the addition of either TPN or DPN. The results of the spectrophotometric experiment were revealed in Fig. 2 (A). Reversibly, reduced pyridine nucleotides were readily oxidized with the addition of acetyl CoA (Fig. 2 (B)). From these figures it would be visualized that the assayed fraction contained alcohol dehydrogenase, which seems to be non-specific for pyridine nucleotides, and aldehyde dehydrogenase which requires CoA. The reaction catalyzed with both enzymes are readily reversible in vitro; in Fig. 2 (A), after reading maximum absorption at $340 \mathrm{~m} \mu$, subsequent addition of acetyl phosphate and CoA to this system gives considerable decrease of the absorption due to the oxidation of reduced coenzymes, followed by the increase of the reduced product (acetaldehyde). In the contents of the Beckman cuvette after the reversible reaction, corresponding amount of acetaldehyde was detected in the complete system, compared with reference cuvette. It would be also demonstrable that acetyl $\mathrm{CoA}$ is stepwise reduced to ethanol via acetaldehyde in the presence of reduced coenzymes of $L$. fermenti. There results have good resemblance to those suggested in $E$. coli and in $\mathrm{Cl}$. kluyveri. However, it would be also postulated that two different enzymes, TPNand DPN-specific alcohol dehydrogenases seem to occur in the fraction of the enzyme.

Impossibility of ethanol formation from pentoses by heterofermentative bacteria means requisite of an oxidative system to be coupled with the reduction of acetyl phosphate which is derived from ketopentose phosphate. There- 


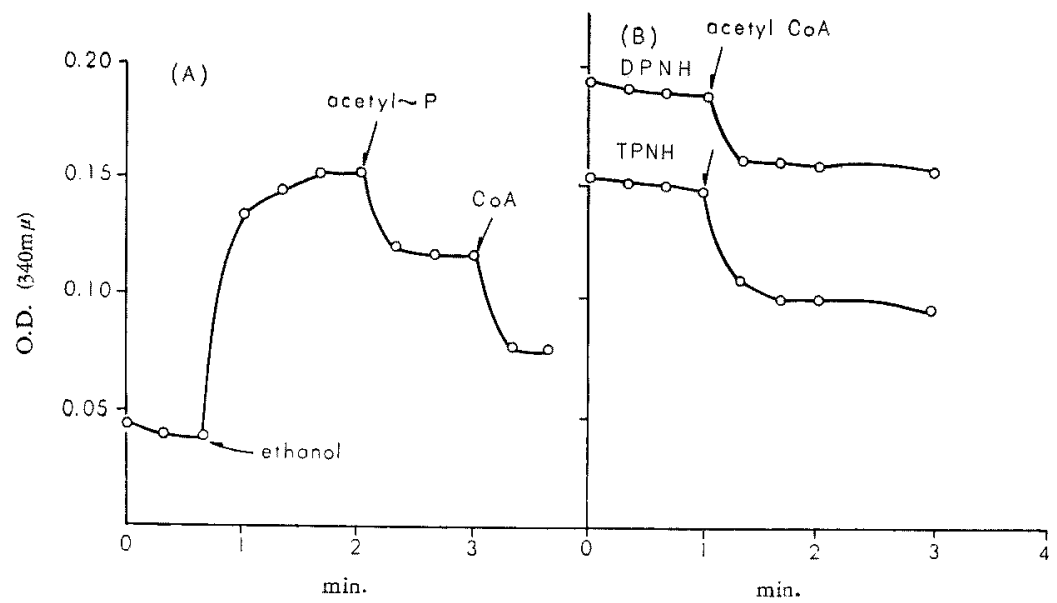

FIG. 2 (A). Coupling of Alcohol Dehydrogenase with Aldehyde Dehydrogenase.

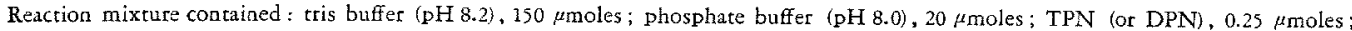
semicarbazide, $20 \mu$ moles; enzyme fraction, $0.05 \mathrm{ml}$, in a total volume of $3.5 \mathrm{ml}$. Subsequent addicions were $200 \mu$ moles of ethanol, $25 \mu$ moles of Liz-acetyl phosphate and 2.2 units of CoA plus $28 \mu$ moles of glutathione, in order. Change of optical density was read before and after addition of substrate at 20 second-intervals in a Beckman cuvette with the light path of $1.0 \mathrm{~cm}$.

(B) Reduction of aceryl COA in the presence of pyridine nucleotides. Reaction conditions were the same as described in (A), except that subsequent addition was $17 \mu$ moles of acetyl CoA.

fore, it would be reasonable to presume that if a synchronizable oxidation system or an appropriate electron donor co-exists with pentose dissimilation by heterofermentative microorganisms ethanol formation from pentoses could, in an optimal environment, be realized.

\section{Coupling with mannitol oxidation.}

As indicated in the previous paper, heterolactic fermenters are readily able to oxidize mannitol to fructose in an aerobic condition. With this standpoint, an assumption could be possible that a couple of electron to be transport, in aerobic experiments, up to air oxygen may be available anaerobically for the reduction of acetyl CoA when D-xylose is simultaneously utilized with the same organism. In other words, this attempt aims to actualize a reverse reaction of $\mathrm{D}$-mannitol production by heterofermentative lactobacilli. Leuc. mesenteroides and L. fermenti which belong to the strain of mannitol-producible, xylose-fermentable heterofermenter. The results shown in Table $\mathrm{V}$ illustrate that mannitol utilization by these organisms was rather difficult in semi-anaerobic (static)
TABLE V. SIMULTANEOUS UTILIZATION OF MANNITOL AND D-XYLOSE BY HETEROFERMENTATIVE MICROOGANISMS

\begin{tabular}{|c|c|c|c|c|c|}
\hline \multirow{2}{*}{$\begin{array}{c}\text { Expt. } \\
\text { No. }\end{array}$} & \multirow{2}{*}{$\begin{array}{c}\text { xylose } \\
\text { utilized }\end{array}$} & \multirow{2}{*}{$\begin{array}{c}\text { mannitol } \\
\text { utilized }\end{array}$} & \multicolumn{3}{|c|}{ products } \\
\hline & & & lactate & ethanol & aceta \\
\hline & $\mathrm{mmol}$ & $\mathrm{mmol}$ & $\mathrm{mmol}$ & $\mathrm{mmol}$ & $\mathrm{mmo}$ \\
\hline 1 & 1.00 & & 0.92 & - & \\
\hline 2 & - & 0.08 & 0.06 & 0.07 & 0.00 \\
\hline 3 & 1.00 & 0.37 & 1.22 & 0.60 & 0.67 \\
\hline 4 & 1.00 & - & 0.88 &..$- \cdot$ & 1.12 \\
\hline 5 & - & 0.12 & 0.09 & 0.09 & 0.00 \\
\hline 6 & 1.00 & 0.28 & 1.16 & 0.48 & 0.83 \\
\hline
\end{tabular}

Each flask contained : 1 mmole of mannitol, 1 mmole of xylose, 2 mmoles of phosphate buffer $(\mathrm{pH} 7.5), 45$ mmoles of $\mathrm{MgCl}_{2}$, $17 \mu \mathrm{mol}$ of $\mathrm{MnCl}_{2}, 1.7 \mathrm{~g}$ of resting cells of $L$. fermenti (Expts. 1,2 and 3) and of Lenc. mesenteroides (Exprs. 4,5 and 6), in $50 \mathrm{ml}$. Incubation was carried out statically for 6 hours at $37^{\circ} \mathrm{C}$. Expt. 1 and 4, without mannitol; Expt. 2 and 5, without xylose; Expt. 3,6 , complete systerm.

incubation, but with the addition of xylose, appreciable amount of mannitol was consumed, and that detectable increase of ethanol formation is manifested in the latter case (Expts. 3 and 6). It would be conceivable that increased amount of ethanol beyond its expected molarity should be due to the transformation of acetyl phosphate from xylose to ethanol.

More distinct evidence was obtained with the 
Table VI. Simultaneous UTILIzation of MANNITOL AND L-ARABINOSE BY HOMOFERMENTATIVE MICROORANISM

\begin{tabular}{cccccc} 
Expt. & \multicolumn{2}{c}{ L-arabinose } & mannitol & \multicolumn{3}{c}{ products } \\
No. & utilized & utilized & $\begin{array}{c}\text { lactate } \\
\text { ethanol }\end{array}$ & acetate \\
& mmol & mmol & mmol & mmol & mmol \\
1 & 0.50 & - & 0.53 & 0.02 & 0.60 \\
2 & - & 0.16 & 0.30 & 0.03 & 0.15 \\
3 & 0.50 & 0.17 & 0.75 & 0.31 & 0.35
\end{tabular}

Experimental conditions were the same as described in Table $\mathrm{V}$, except that 0.5 mmole of $\mathrm{t}$-arabinose and $1.5 \mathrm{~g}$ of resting cells of Lu arabinosus were used. Expt. 1, without mannitol; Expt. 2, without arabinose; Expt. 3, complete system.

experiments using $L$. arabinosus which belongs to the strain of D-mannitol-utilizable, L-arabinosefermentable homofermenter (Table VI). Only trace amount of ethanol is produced from each separated substrate, but when simultaneous occurrence of both substrate (Expt. 3) happened in the incubated broth, large amount of ethanol is produced probably because a couple of electron liberated with the dehydrogenation of mannitol1-phosphate to fructose-6-phosphate serves in vivo for the reduction of acetyl phosphate derived from pentose phosphate. Satisfactory decision to justify these presumption will be achieved only by a series of works using xylose$1-\mathrm{C}^{14}$.

2. Supply of reduced methyl viologen.

At the first stage, methyl viologen $\left(E_{0}{ }^{\prime}\right.$ : $-446 \mathrm{mV}$ ) undergoes extracellular reduction with platinum asbestos in hydrogen gas phase, then the reduced dye penetrates the cell membrane of microorganism, as a donor of electron, which is finally accepted with ethanol precursors mediated pyridine nucleotides $\left(\mathrm{E}_{0}{ }^{\prime}:-320 \mathrm{mV}\right)$. For good results two indispensaple factors must be controlled; one is that successive and stable reduction of oxidized methyl viologen takes place without serious inhibition on other internal redox systems, and the other is that adequate permeability for the reduced dye is gifted to the bacterial cell membrane.

From view point of practical technique, an absolutely anaerobic gas phase was required for the infinite production of reduced methyl viologen in circulation. Another important factor is the adjustment of $\mathrm{pH}$ which shows direct effect on the stability of the reduced dye. In a 500 ml-round bottom flask with a rubber stopper, through which an outlet and an inlet glass tube for the gas exchange were installed, the reaction mixture containing cell suspension, substrate, dye and platinum asbestos was incubated in a shaking incubator at $30^{\circ} \mathrm{C}$ or continuously stirred on a magnetic stirrer, in hydrogen gas phase. The $\mathrm{pH}$ of the contents was adjusted with dropwise addition of $0.1 \mathrm{~N}$ $\mathrm{NaOH}$ in order to to decolorize blue tint of the reduced dye. After an expected period of incubation elapsed, the contents were analyzed.

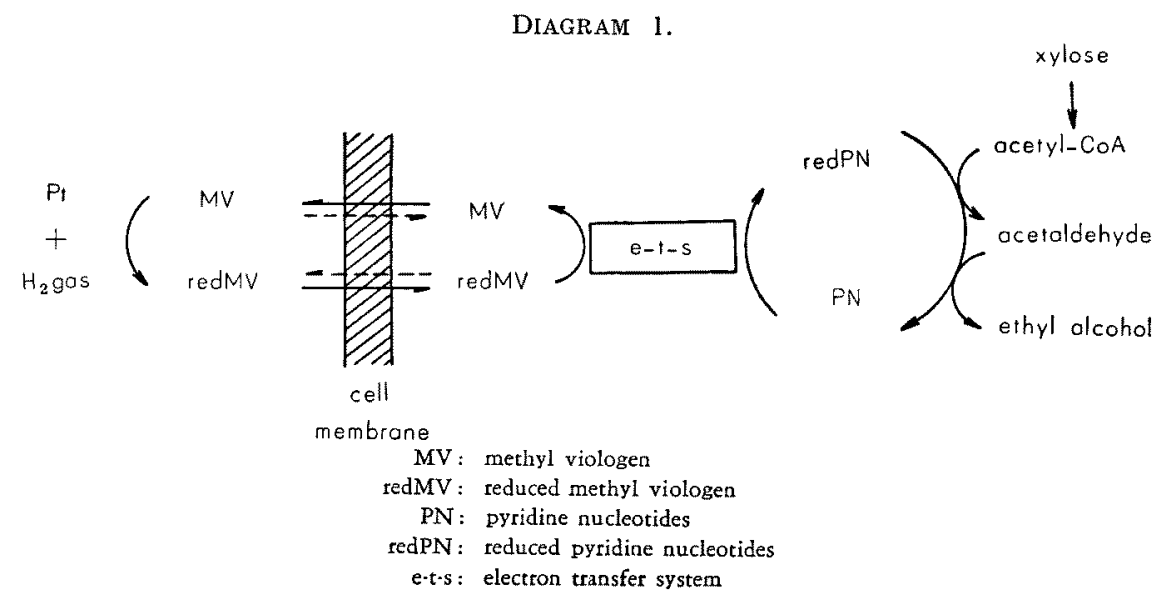


Table VII. Ethanol Formation fRom D-XYLOSE By Resting Cells of L. fermenti AND L. Xylosus

\begin{tabular}{ccccc} 
Expt. No. & $\begin{array}{c}\text { xylose } \\
\text { utilized }\end{array}$ & \multicolumn{3}{c}{ products } \\
& lactate & acetate & ethanol \\
& mmol & $\begin{array}{c}\text { mmol } \\
\text { mmol }\end{array}$ & mmol \\
1 & 0.86 & 0.78 & 0.89 & trace \\
2 & 0.72 & 0.63 & 0.42 & 0.26 \\
3 & 0.42 & 0.33 & 0.23 & 0.31 \\
4 & 0.76 & 0.68 & 0.83 & trace \\
5 & 0.51 & 0.44 & 0.32 & 0.14 \\
6 & 0.53 & 0.42 & 0.35 & 0.11
\end{tabular}

Reaction mixture contained: 2 mmoles of phosphate buffer (pH 7.5), 3 mmoles of tris buffer ( $\mathrm{pH} 7.8$ ), 1 mmole of xylose, $20 \mu$ moles of methyl viologen chloride, $10 \mathrm{mg}$ of platinum asbes. tos, $25 \mu$ moles of $\mathrm{MgCl}_{2}$ and $1.2 \mathrm{~g}$ of resting cells of $L$. fermenti (Expts. 1,2 and 3) or $1.5 \mathrm{~g}$ of resting cells of L. xylosus (Expts. $4,5$ and 6$)$; in $50 \mathrm{ml}$. The mixture was stirred by a magnetic stirrer under liydrogen gas phase for 5 hours. In Expts. 1 and 4, methyl viologen was not added.

TABLE VIII. ETHANOL FORMATION FROM L-Arabinose by Resting Cellis oF

$L$. mesenteroides AND $L$. arabinosus

$\begin{array}{ccccc}\text { Expt. No. } & \begin{array}{l}\text { arabinose } \\ \text { utilized }\end{array} & \begin{array}{c}\text { products } \\ \text { lactate } \\ \text { mmol }\end{array} & \begin{array}{c}\text { acetate } \\ \text { mmol }\end{array} & \begin{array}{c}\text { ethanol } \\ \text { mmol }\end{array} \\ 1 & 0.83 & 0.76 & 0.92 & 0 \\ 2 & 0.56 & 0.44 & 0.61 & 0.07 \\ 3 & 0.39 & 0.32 & 0.45 & 0.05 \\ 4 & 0.55 & 0.49 & 0.51 & 0 \\ 5 & 0.48 & 0.44 & 0.45 & \text { trace } \\ 6 & 0.33 & 0.29 & 0.38 & \text { trace }\end{array}$

Experimental conditions were the same as described in Table VII. except that $1.15 \mathrm{~g}$ of resting cells of Leuc. mesenteroides (Expts. 1,2 and 3) or $2.0 \mathrm{~g}$ of resting cells of L a a abinosus (Expts. 4,5 and 6) was added. Expts. 1 and 4, without methyl viologen.

Some typical results among many data are presented in Table VII.

Although complete disappearance of volatile acid was not yet practicable, the data in Table VII indicate that approximately half amount of acetic acid, if normally, to be produced seems to have been transformed into ethyl alcohol. Thus this mode of fermentation appears actually corresponding, except evolution of carbon dioxide, with that of gluconate fermentation by the same organism in anaerobic conditions:

Xylose + red $\mathrm{MV}^{*} \rightarrow$ Lactate $+\frac{1}{2}$ Acetate +

Ethanol + ox $\mathrm{MV}^{* *}$

Gluconate $\rightarrow$ Lactate $+\frac{1}{2}$ Acetate $+\frac{1}{2}$ Ethanol

$+\mathrm{CO}_{2}+\mathrm{H}_{2} \mathrm{O}$

* reduced methyl viologen

** oxidized methyl viologen
On the contrary, the results in Table VIII show that ethyl alcohol is poorly produced from arabinose even by the microorganisms which can readily utilize arabinose in anaerobic circumstances. Satisfactory interpretation to the difficulty of ethanol formation from arabinose is still impossible though it would be conceivable that also with respect to redox system of $L$. arabinosus participating in ethanol formation (alcohol dehydrogenase, aldehyde dehydrogenase and phosphotransacetylase) might be enough active to produce ethanol from acetyl phosphate (Table VI).

\section{DISCUSSION}

In the normal heterolactic fermentation it seems to be difficult to detect acetaldehyde as an intermediate of ethanol formation because of its rapid reduction to ethanol without transient extracellular accumulation of acetaldehyde. With the addition of semicarbazide, however, pyruvate and acetaldehyde, even during anaerobic fermentation of glucose, are accumulated instead of their reduction of lactate and ethanol, respectively, the quantities of which are sufficient to be recovered for estimation. This valuable view would extend the knowledge of quantitative investigation of the products formed by heterofermentative microorganisms.

With respect to coenzyme dependence, it has been reported that, in ethanol formation from acetyl $\mathrm{CoA}$ in the extract of $\mathrm{Cl}$. kluyveri or $E$. coli, reduced DPN is absolutely required. On the contrary, in L. fermenti alcohol and aldehyde dehydrogenases appear to have no strict specificity for pyridine nucleotides, although CoAdependent reduction of acetyl phosphate to acetaldehyde proves to be more accelerated with TPN than with DPN. The presumption of the occurrence of two different dehydrogenases (DPN- and TPN-linked) might well be ruled out since glucose-6-phosphate and 6-phosphogluconate dehydrogenases, which should couple with alcohol- and aldehyde dehydrogenases in vivo, are also found to be non-specific for pyridine nucleotides of the same microorganism. Further clarification of these phenomena still 


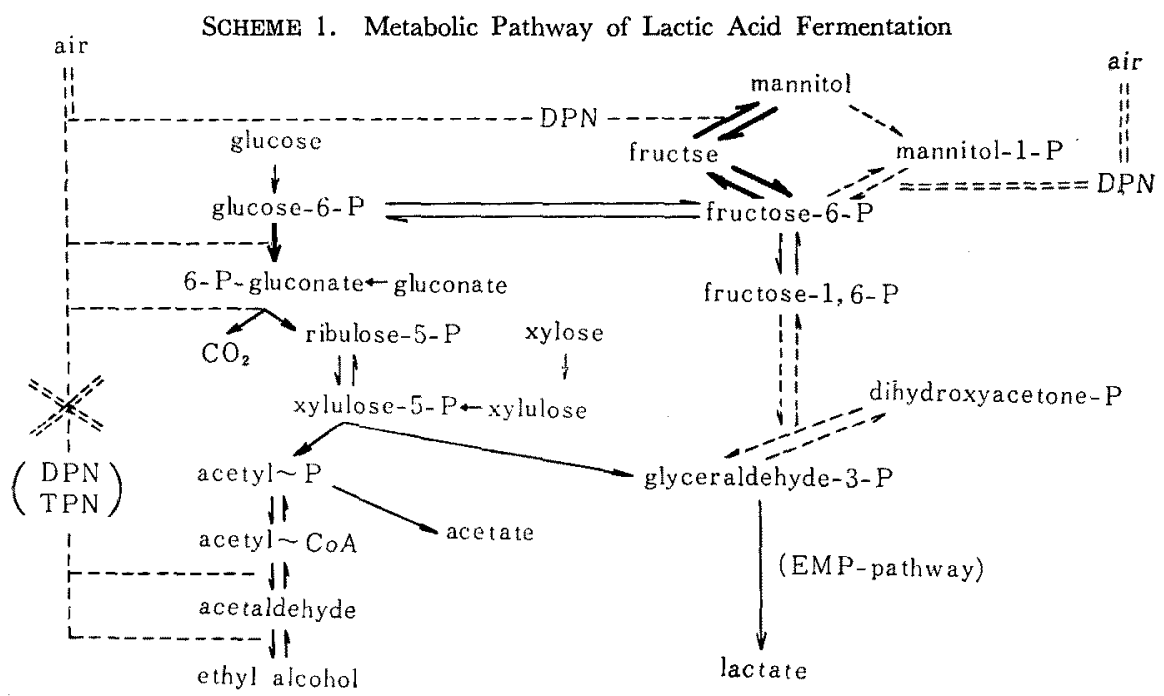

Single dotted lines tepresent coupling system of dehydrogenases (anaerobic fermentation), and double dotted lines electron transport to air oxygen (aerobic fermentation). Bold arrow heads indicate metabolic routes characteristic of heterofermentative microorganisms, dotted arrow heads routes characteristic of homofermentative microorganisms, and fine arrow heads common routes to both species.

remains to be researched. Summarizing many data and discussions, the authors suggest a reasonable metabolic pathway of lactic acid fermentation in which elucidation for the accumulation and utilization of mannitol by lactic acid bacteria is included (Scheme I).

With the procedures for the experiments using methyl viologen more satisfactory results would not be obtained unless velocity of pentose degradation efficiently slides in continuous reproduction-cycle of reduced methyl viologen, linking between extra- and intracellular metabolic pools. Besides this difficulty, another problem would await resolution that other electron transfer systems contained in the microorganisms are checked by descendence of redox potential towards a degree of platinum electrode which is continuously functioning in a fermentation broth. Thereby these two main barriers, above pointed out, would obstruct prospective application of the dye method to industrial region.

\section{SUMMARY}

1. Pyruvate and acetaldehyde were detected as intermediates in the pathway of heterolactic fermentation by L. fermenti.
2. Acetaldehyde was accumulated aerobically as an oxidation product of ethanol in the presence of semicarbazide.

3. Dismutation of acetaldehyde to ethanol and acetate was observed when acetaldehyde was added to the system of glucose fermentation.

4. Alcohol dehydrogenase in an ammonium sulfate fraction catalyzes both DPN- and TPNdependent oxidation of ethanol to acetaldehyde. Acetyl CoA was reduced in the presence of either TPN or DPN with the same fraction.

5. By coupling of $\mathrm{D}$-xylose degradation with mannitol utilization appreciable increase of ethyl alcohol was observed with resting cells of heterolactic microorganisms.

6. With the continuous supply of reduced methyl viologen approximately half molarity of acetate to be produced from D-xylose was transformed to ethyl alcohol in an absolutely anaerobic condition. From L-arabinose only poor amount of ethyl alcohol was produced by both strains of microorganisms.

7. A metabolic pathway of lactic acid fermentation including D-mannitol fermentation was suggested. 